\title{
Characterization of hydrolytic degradation of polylactic acid/rice hulls composites in water at different temperatures
}

\author{
B. S. Ndazi $i^{1,2 *}$ S. Karlsson ${ }^{1}$ \\ ${ }^{1}$ Department of Fibre and Polymer Technology, Royal Institute of Technology (KTH), 100 44, Stockholm, Sweden \\ ${ }^{2}$ Permanent address: Department of Mechanical and Industrial Engineering, College of Engineering and Technology, \\ University of Dar es Salaam, P.O. Box 35131, Dar es Salaam, Tanzania
}

Received 12 July 2010; accepted in revised form 9 October 2010

\begin{abstract}
Hydrolytic degradations of polylactic acid/rice hulls (PLA/RH) composites with various rice hulls contents due to water absorptions at 23,51 and $69^{\circ} \mathrm{C}$ were investigated by studying the thermal properties, chemical composition, molecular weight, and morphology of the degraded products. The results have attested that the stability of PLA/RH composites in water depends slightly on rice hulls contents but it is significantly influenced by water temperature. Water absorption in 30 days at $23^{\circ} \mathrm{C}$ was between 0.87 and $9.25 \%$ depending on rice hull contents. However, at thermophilic temperatures, the water absorption and degradation of these products were increased significantly. Saturations were achieved in less than 25 and 9 days at $51{ }^{\circ} \mathrm{C}$ and $69^{\circ} \mathrm{C}$, respectively, while hydrolytic degradation was demonstrated by an increase in fragility and development of crystallinity. At $69^{\circ} \mathrm{C}$, there were significant reductions of the decomposition and glass transition temperatures of the polymer by $13^{\circ} \mathrm{C}$. These changes were associated with the reduction of the molecular weight of PLA from $153.1 \mathrm{kDa}$ to $\sim 10.7 \mathrm{kDa}$ due to hydrolysis of its ester group.
\end{abstract}

Keywords: biodegradable polymers, polylactic acid, rice hulls, hydrolytic degradation, molecular weight

\section{Introduction}

There has been a growing interest in the development of environmentally benign composites based on biodegradable poly(lactic acid) (PLA) polymer and various lignocellulosic materials such as kenaf [1, 2], flax [3], hemp [4], bamboo [5, 6], wood fibers [7], and reed fibers [8]. Addition of lignocellulosic materials in PLA is intended to improve the properties of this polymer without compromising its biodegradability. Although there has been very little work in the development of biodegradable polymer composites using rice hulls [1], several studies have demonstrated the potential of rice hulls in polymer composites [9-13]. Rice hulls are siliceous lignocellulosic residues, which have moderate water resistance and stability against degradation. It may be interesting therefore to find out how these properties can affect the biodegradability of PLA.

PLA is a biodegradable polymer, which is naturally hydrophilic due to its polar oxygen linkages. It contains a methyl side group, which confers hydrophobic properties to this polymer [14]. The natural hydrophilic characteristic of PLA is responsible for its moderate decomposition in accordance with the surrounding moisture and temperature. The first stage of PLA degradation is usually the reduction of its molecular weight by hydrolysis to $<10 \mathrm{kDa}$ before it becomes biodegradable. The hydrolysis of PLA occurs by random cleavage of the $-\mathrm{C}-\mathrm{O}-$ ester bond by water molecules. The hydrolysis products, which may contain fragments of lactic acid, oligomers and other water soluble products, can then be con-

${ }^{*}$ Corresponding author, e-mail: bndazi@udsm.ac.tz
(C) BME-PT 
sumed by microorganisms to produce carbon dioxide $\left(\mathrm{CO}_{2}\right)$, water $\left(\mathrm{H}_{2} \mathrm{O}\right)$ and solid biomass [15]. This reaction can be increased under acidic or basic conditions or in the presence of high moisture and high temperature $[16,17]$. Previous studies have shown that PLA is moderately stable in water at mesophilic temperatures $\left(15-40^{\circ} \mathrm{C}\right)$. It can absorb between 0.7 and $1 \%$ of water in 30 days [18] or slightly higher at longer immersion periods [2] at these temperatures. The absorption of water by PLA biocomposites at these temperatures can lead to moderate change in their properties depending on filler contents $[2,18]$. Since hydrolysis of PLA is influenced by ambient moisture and temperature, it is possible to accelerate the diffusion of water and hence increase the hydrolysis or degradation of this polymer by subjecting it to thermophilic temperatures above $50^{\circ} \mathrm{C}$. In this report, the degradation of PLA/RH composites due to water absorption at 23,51 and $69^{\circ} \mathrm{C}$ was investigated. The tests were carried out by immersing the PLA products in water until they were completely saturated. Their degradation was studied by thermal analysis, infrared spectroscopy, molecular weight analysis, and surface morphology analysis.

\section{Materials and methods}

\subsection{Materials and preparations}

Rice hulls were obtained from rice mills in Tanzania. A commercial grade PLA (Ingeo 3051D) in pellets form with a melt flow index of $1-2.5 \mathrm{~g} / \mathrm{min}$, from RESINEX Nordic AB Sweden, was used as a resin. The resin had the following specifications: specific gravity 1.24; melting temperature between 145 and $155^{\circ} \mathrm{C}$, crystallization temperature from 95 to $120^{\circ} \mathrm{C}$ and the glass transition temperature ranging from 55 to $58^{\circ} \mathrm{C}$. Dicumyl peroxide (DCP)-98\% (Aldrich) and maleic anhydride (MA) briquettes M188-99\% (Aldrich), purchased from Sigma Aldrich Sweden AB, were used as free radical initiator and coupling agent, respectively.

The PLA polymer and MA were prepared separately by grinding though a $1 \mathrm{~mm}$ sieve. The rice hulls (RH) were also ground though a 1-mm sieve and were dried overnight in an oven at $102^{\circ} \mathrm{C}$ to remove residual moisture. The ground rice hulls were designated as untreated rice hulls (URH).

\subsection{Preparation of the composites}

The composites were prepared by mixing different ratios of ground PLA resin and dry rice hulls. The amount of MA in the composites was controlled by the proportion of RH (i.e. 7\% RH) while DCP was fixed at $7 \%$ MA. The mixture was tumbled in a mechanical mixer that rotates in three axes for about 30 minutes. This was followed by vacuum drying the mixture at $80^{\circ} \mathrm{C}$ for about 6 hours and then pressing under vacuum in a $400 \mathrm{kN}$ compression moulding machine (Fontune Presses) at $190^{\circ} \mathrm{C}$ and $10 \mathrm{MPa}$ for 5 minutes to produce $140 \mathrm{~mm} \times$ $52 \mathrm{~mm} \times 2 \mathrm{~mm}$ PLA composites with various contents of rice hulls. The PLA without rice hulls was designated as PLA-100 and those which contained the rice hulls were designated as PLA/URH 80/20, PLA/URH 70/30 and PLA/URH 60/40 where the digits refer to the proportion of PLA and RH in the composites, respectively.

\subsection{Water absorption test}

Water absorption tests were carried out in accordance with ASTM D570-98 guideline by submerging five rectangular test specimens with $20 \times 50 \times$ $2 \mathrm{~mm}^{3}$ dimensions into water at $23 \pm 1{ }^{\circ} \mathrm{C}, 51 \pm 0.5^{\circ} \mathrm{C}$ and $69 \pm 1{ }^{\circ} \mathrm{C}$ until they were completely saturated. All test specimens were dried in a conventional oven at $51 \pm 0.5^{\circ} \mathrm{C}$ for 24 hours prior to immersion in water. The test specimens were periodically removed from water and dried thoroughly with tissue papers before recording their weight gains. After saturation, all the test specimens were redried to constant weights at $51 \pm 0.5^{\circ} \mathrm{C}$ for 24 hours at the end of the test.

Absorption of water into the polymer composite is controlled by diffusion. If the diffusion follows Fickian behavior, an increase in weight can be described in terms of the diffusion coefficient, $D$, and the maximum moisture content, $M_{\mathrm{m}}$ as shown by Equation (1) $[5,18]$.

$\frac{M_{\mathrm{t}}}{M_{\mathrm{m}}}=\frac{4}{h}\left(\frac{D}{\pi}\right)^{1 / 2} \cdot t^{1 / 2}$

where $M_{\mathrm{t}}$ is the degree of water-sorption at time $t$; $M_{\mathrm{m}}$ is the water-sorption amount at equilibrium sorption time; $h$ is the thickness of the specimen; and $t$ is the water-sorption time. 
The diffusion coefficient, $D$, may be given by Equation (2) from the slope $(k)$ of the initial linear portion of the absorption curve $M_{\mathrm{t}}$ against $t^{1 / 2}$.

$$
D=\pi\left(\frac{k h}{4 M_{\mathrm{m}}}\right)^{2}
$$

\subsection{Visual inspection of physical changes}

Changes in the physical appearance such as color and flexibility of the test specimens were also monitored during the test.

\subsection{Infrared spectroscopy analysis}

Hydrolytic degradations of PLA and PLA/RH composites with different contents of rice hulls were also studied by infrared spectroscopy using a Fourier Transform Infrared (FTIR)-spectrometer 2000 system (Perkin Elmer). Each sample was run in duplicate and the results presented are the average of two runs. Samples were dried at $51 \pm 0.5^{\circ} \mathrm{C}$ for 24 hours before the analysis.

\subsection{Thermal analysis}

The influence of hydrolytic degradation on the thermal transitions and thermal stability of PLA and PLA/RH composites was determined by scanning calorimetry 1 (DSC1) and thermal gravimetric analysis (TGA) TGA/SDTA851 systems (Mettler Toledo AB, Sweden). The DSC1 system was calibrated using the melting temperature and enthalpy of indium as standard. The control samples from the non-immersed PLA and PLA/RH composites were ground through $1 \mathrm{~mm}$ test sieve while those from water soaked PLA and the PLA/RH composites were cut or crushed by hand. All test samples were accurately weighed into $100 \mu \mathrm{l}$ aluminium pans to within $8.50 \mathrm{mg}$. An empty pan was used as a reference and each test sample was run in duplicate. The test was started by holding the samples at $25^{\circ} \mathrm{C}$ for $5 \mathrm{~min}$ utes and then raising the temperature to $200^{\circ} \mathrm{C}$ at $10^{\circ} \mathrm{C} / \mathrm{min}$ under $50 \mathrm{ml} / \mathrm{min}$ of $\mathrm{N}_{2}$ gas. The samples were isothermally heated at $200^{\circ} \mathrm{C}$ for 3 minutes and subsequently cooled back to $25^{\circ} \mathrm{C}$ at $-10^{\circ} \mathrm{C} / \mathrm{min}$ and held at that temperature for 3 minutes before heating again at the same rate to $200^{\circ} \mathrm{C}$. All DSC measurements were taken from the second heat cycle in order to eliminate the influence of sample history.
Crystallinity of the PLA polymer was calculated from the DSC results using the melting enthalpy $\left(\Delta H_{\mathrm{m}}{ }^{*}\right)$ of a pure crystalline PLA. The $\Delta H_{\mathrm{m}}{ }^{*}$ value used to estimate the crystallinity is either $135 \mathrm{~J} / \mathrm{g}$ suggested by Mitaya and Masuko [19] or $93.7 \mathrm{~J} / \mathrm{g}$ calculated by Fischer et al. [20]. In this study, Mitaya and Masuko's value was used in conjunction with the Equation (3), which has been used elsewhere [21].

$\chi_{\mathrm{c}}=\frac{\Delta H_{\mathrm{m}}}{\Delta H_{\mathrm{m}}} \cdot 100 \%$

where $\Delta H_{\mathrm{m}}$ is the melting enthalpy of PLA in the composite.

Thermal stability measurements of the PLA and PLA/RH composites were carried out between $25^{\circ} \mathrm{C}$ and $700^{\circ} \mathrm{C}$ at $10^{\circ} \mathrm{C} /$ min under $\mathrm{N}_{2}$ environment at $50 \mathrm{ml} / \mathrm{min}$ using TGA technique. The sample weight was maintained within $12.0 \pm 0.5 \mathrm{mg}$. The samples were initially dried at $51 \pm 0.5^{\circ} \mathrm{C}$ for 24 hours before the analysis.

\subsection{Molecular weight analysis}

Molecular weights reduction of PLA due to water absorptions were measured by TripleSEC Size Exclusion Chromatography (SEC) system using THF $(1.0 \mathrm{ml} / \mathrm{min})$ as the mobile phase was performed at $35^{\circ} \mathrm{C}$ using a Viscotek TDA model 301 equipped with two T5000 columns with porous styrene divinylbenzene copolymer $(300 \mathrm{~mm} L \times$ $7.8 \mathrm{~mm}$ ID, exclusion limit MW polystyrene: $400000 \mathrm{kDa}$ ) from Malvern (UK), a VE $2500 \mathrm{GPC}$ autosampler, a VE 1121 GPC solvent pump, and a VE 5710 GPC degasser from Viscotek Corp. (the Netherlands). The samples were prepared by dissolving $\sim 20 \mathrm{mg}$ of PLA into $10 \mathrm{ml}$ of THF. After filtration, the samples were transferred into $2 \mathrm{ml}$ vials for analysis.

\subsection{Morphological analysis}

The influence of hydrolytic degradation on the fracture surfaces of PLA and PLA/RH composites was examined by Hitachi Field Emission SEM S-4800 system (Spectral Solutions AB, Sweden). The observations were made on the cross sections of the fracture surfaces of gold sputtered samples and also on the surfaces of these samples, which were in contact with water. All samples were prepared by breaking 
with hand except those that were immersed at $23^{\circ} \mathrm{C}$, which required freeze-drying in liquid nitrogen prior to breaking.

\section{Results and discussion}

\subsection{Water absorption and physical changes}

Figures 1a to $1 \mathrm{c}$ show the results of water absorption by PLA and PLA/RH composites at 23, 51 and $69^{\circ} \mathrm{C}$, respectively. The diffusion of water into these products was higher during the first periods and decreased gradually until they were saturated suggesting a classical Fickian diffusion phenomenon. A mixed diffusion behavior has been reported previously in other PLA products $[5,18,2]$. However, it is shown that most of the PLA products that were immersed at $69^{\circ} \mathrm{C}$ (Figure 1c) did not reveal consistent saturations and therefore failed to exhibit Fickian diffusion phenomenon. At 51 and $69^{\circ} \mathrm{C}$ temper-
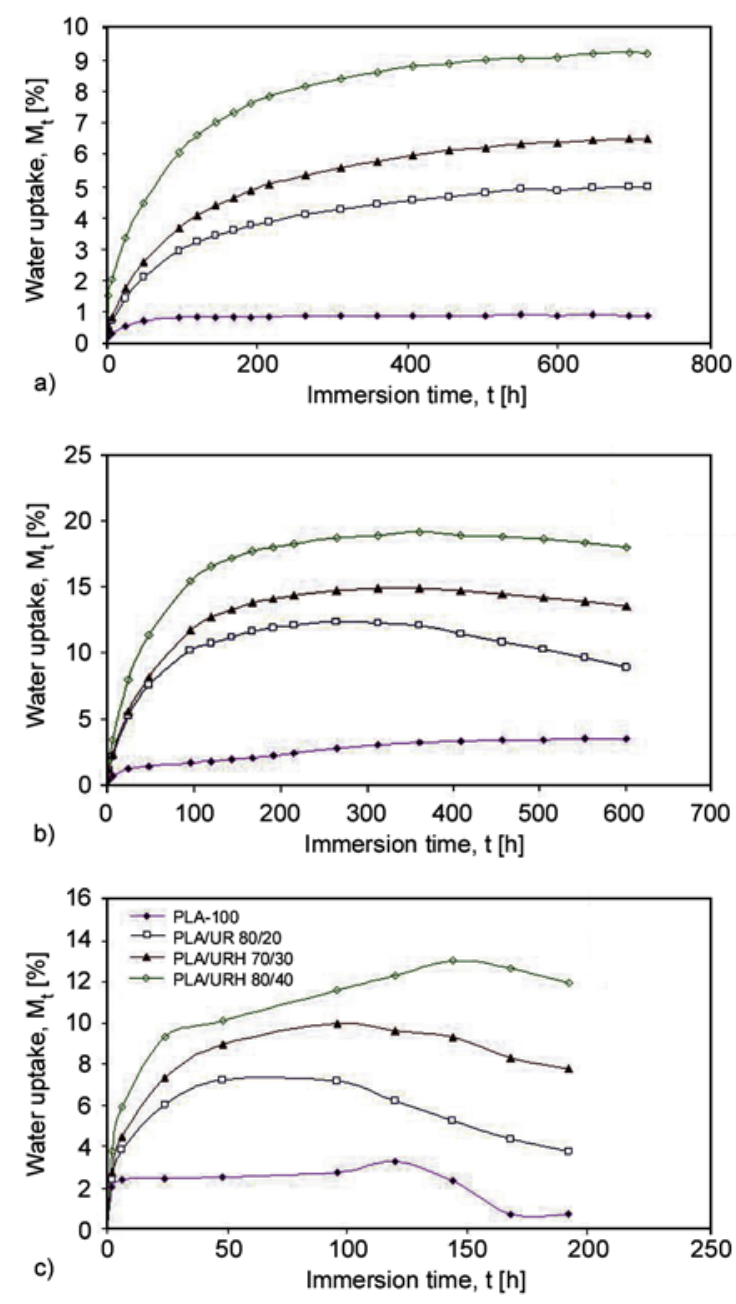

Figure 1. Moisture absorption in PLA/RH composites immersed in water at (a) $23^{\circ} \mathrm{C}$, (b) $51{ }^{\circ} \mathrm{C}$ and (c) $69^{\circ} \mathrm{C}$ atures, the PLA/RH composites did not stabilize long at the saturation points and the time to reach that saturation was also significantly reduced. This was probably due to increased hydrolysis and leaching of the rice hulls and water soluble polymer products from the composites. Visual observations revealed that PLA products, which were immersed at $69^{\circ} \mathrm{C}$, lost the transparency and became fragile from the third day. The composites that were immersed at 51 and $69^{\circ} \mathrm{C}$ became fragile during the testing period. On the contrary, the PLA products that were immersed at $51^{\circ} \mathrm{C}$ developed hardness while undergoing hydrolysis. This physical anomaly was examined by studying the morphologies of the fracture surfaces of all PLA and PLA/RH composites. PLA products are generally stable against hydrolysis at mesophilic temperatures [15] and absorb little amount of water $[2,18]$. However, the results have attested that the hydrolysis and water absorption of these products can be accelerated significantly by simply subjecting them above the softening temperature of PLA.

By using the classical Fickian diffusion phenomenon, it was possible to estimate the diffusion parameters of some of the composites, which exhibited this behavior. The results shown in Table 1 generally corroborate the proposition that the rate of water diffusion into the composites increases at higher immersion temperatures with the exception of PLA and PLA/RH composites with $40 \%$ rice hulls content (PLA/URH 60/40) which were immersed at $51{ }^{\circ} \mathrm{C}$. The results show further that weight losses occurred only in the composites that were immersed at 51 and $69^{\circ} \mathrm{C}$. This loss is attributed to the leaching of rice hulls and water soluble products mainly lactic acid and probably low molecular weight oligomers from the composite during the degradation of PLA in water. The weight gains shown by all the products, which were immersed at $23^{\circ} \mathrm{C}$, attests further the stability of PLA in water at mesophilic temperatures. On the contrary, the weight gain revealed by PLA that was immersed at $51^{\circ} \mathrm{C}$ may be explained by different phenomena. However, it is worthy to note that this product hardened while undergoing water absorption. This could be attributed to aging of the product and hydrolysis of the amorphous domains. As expected, the diffusion of water into the composites increased with the increase of rice hulls content. This agrees with the 
Table 1. Diffusion parameters of PLA and PLA/RH composites

\begin{tabular}{|c|c|c|c|c|}
\hline Product & $\begin{array}{c}\text { Temp } \\
{\left[{ }^{\circ} \mathrm{C}\right]}\end{array}$ & $\begin{array}{l}\mathbf{M}_{\mathbf{m}} \\
{[\%]}\end{array}$ & $\begin{array}{l}\mathrm{D} \cdot 10^{-5} \\
{\left[\mathrm{~mm}^{2} / \mathrm{s}\right]}\end{array}$ & $\begin{array}{c}\text { Weight gain of re-dried product } \\
{[\%]}\end{array}$ \\
\hline \multirow{3}{*}{ PLA-100 } & 23 & 0.87 & 0.665 & -0.07 \\
\hline & 51 & 3.57 & 0.223 & -0.21 \\
\hline & 69 & - & - & 3.16 \\
\hline \multirow{3}{*}{ PLA/URH 80/20 } & 23 & 4.98 & 0.120 & -3.15 \\
\hline & 51 & 12.35 & 0.172 & 8.85 \\
\hline & 69 & 7.19 & 1.676 & 12.10 \\
\hline \multirow{3}{*}{ PLA/URH 70/30 } & 23 & 6.49 & 0.113 & -0.25 \\
\hline & 51 & 14.95 & 0.148 & 4.40 \\
\hline & 69 & 9.96 & 1.164 & 10.31 \\
\hline \multirow{3}{*}{ PLA/URH 60/40 } & 23 & 9.25 & 0.303 & -1.46 \\
\hline & 51 & 19.14 & 0.195 & 3.63 \\
\hline & 69 & 1.00 & - & 9.89 \\
\hline
\end{tabular}

previous studies $[5,18]$ by demonstrating the role of rice hulls as hydrophilic fillers in the composite.

\subsection{Thermal properties}

The influence of hydrolytic degradations on the thermal properties of PLA/RH composites as measured by DSC 1 system, are shown in Figure 2 and the summary is given in Table 2. As shown in Figure $2 \mathrm{a}$, peaks ascribed to crystallization and melting of neat PLA did not appear during the re-heating cycle. Absence of the crystallization peak implies that the pellets were more amorphous. It is shown further that the crystallinity of PLA was slightly reduced during immersion of the PLA products in water at $23^{\circ} \mathrm{C}$ for 30 days. This is explained by a decrease of the crystallization and melting peaks
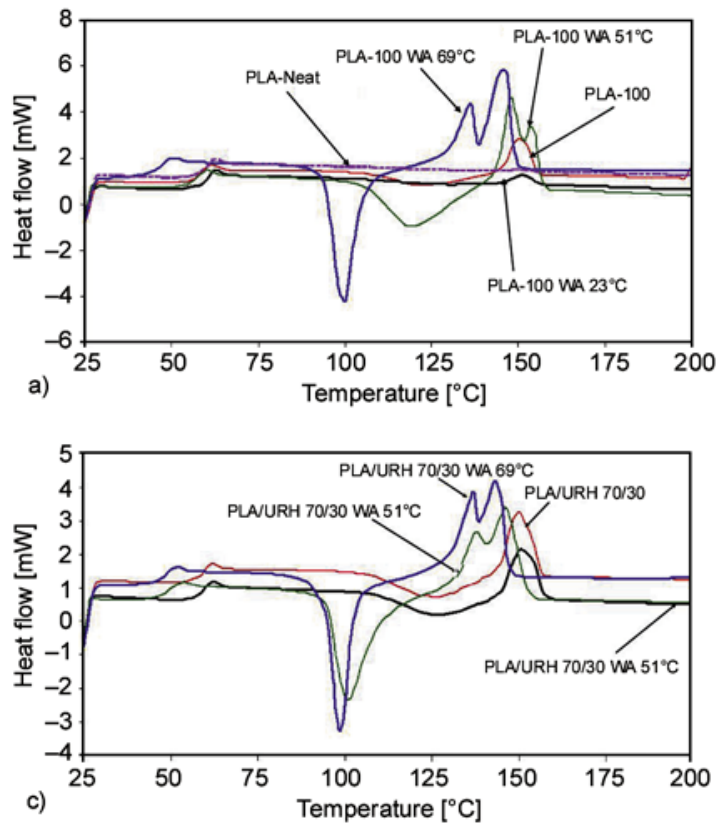

observed on the thermogram of this sample compared with the control PLA (PLA 100). The results show that the crystallization peaks of the composites were somewhat enhanced after addition of rice hulls in PLA (Figures $2 \mathrm{~b}$ to $2 \mathrm{~d}$ ). These peaks increased considerably due to hydrolysis at higher temperatures. They were much stronger in the composites than in PLA at $51^{\circ} \mathrm{C}$ and increased substantially at $69^{\circ} \mathrm{C}$ in PLA ad well as in the composites. The large melt crystallizations shown in these products are evidence of enormous transformation of amorphous PLA into crystalline phases as the polymer was undergoing hydrolysis in water at 51 and $69^{\circ} \mathrm{C}$ temperatures. The results also seem to suggest further that the presence of rice hulls somehow enhanced the crystallization of PLA during water
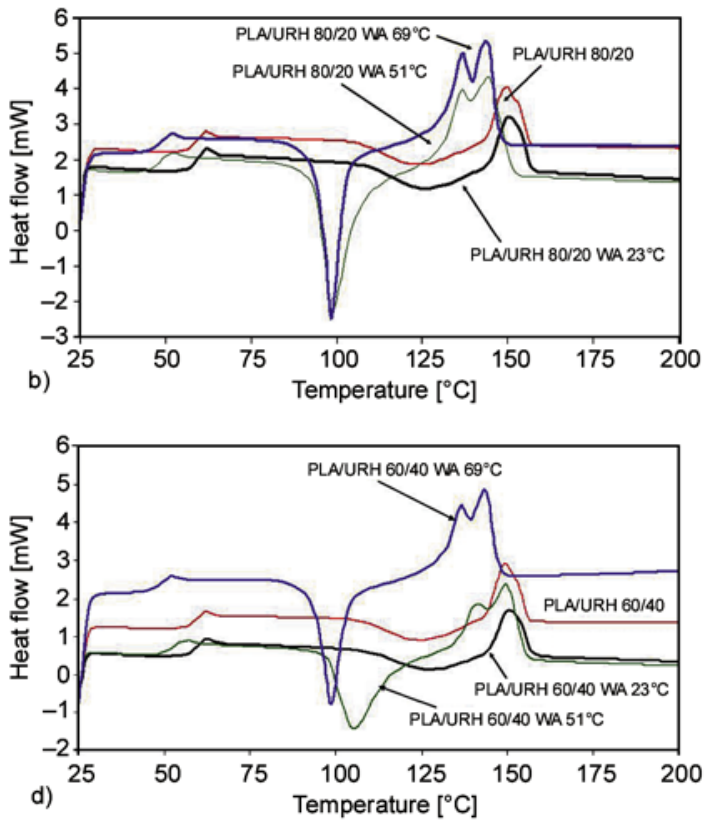

Figure 2. DSC thermograms of (a) PLA, (b) PLA/URH 80/20 composites, (c) PLA/URH 70/30 composites, and (d) PLA/URH 60/40 composites before and after water absorption 
Table 2. Thermal properties of PLA/RH composites due to water absorption at different temperatures

\begin{tabular}{|c|c|c|c|c|c|c|}
\hline Product & $\begin{array}{c}\text { Immersion temp } \\
{\left[{ }^{\circ} \mathrm{C}\right]}\end{array}$ & $\begin{array}{c}\mathbf{T}_{\mathbf{g}} \\
{\left[{ }^{\circ} \mathbf{C}\right]}\end{array}$ & $\begin{array}{c}\mathbf{T}_{\mathbf{c}} \\
{\left[{ }^{\circ} \mathbf{C}\right]}\end{array}$ & $\begin{array}{l}{ }^{*} \mathbf{T}_{\mathbf{m}} \\
{\left[{ }^{\circ} \mathbf{C}\right]}\end{array}$ & $\begin{array}{l}\Delta \Delta \mathbf{H}_{\mathrm{m}} \\
{[\mathrm{J} / \mathrm{g}]}\end{array}$ & $\begin{array}{c}\chi_{c} \\
{[\%]}\end{array}$ \\
\hline \multirow{4}{*}{ PLA-100 } & - & 59.0 & 122.5 & 150.0 & 8.6 & 6.4 \\
\hline & 23 & 59.1 & 126.5 & 151.1 & 1.9 & 1.4 \\
\hline & 51 & 56.2 & 119.6 & 148.0 & 26.1 & 19.3 \\
\hline & 69 & 46.4 & 99.8 & 145.6 & 41.6 & 30.8 \\
\hline \multirow{4}{*}{ PLA/URH 80/20 } & - & 57.9 & 123.4 & 149.3 & 10.6 & 6.3 \\
\hline & 23 & 58.1 & 125.8 & 150.5 & 8.9 & 5.3 \\
\hline & 51 & 49.0 & 99.0 & 144.6 & 29.9 & 17.7 \\
\hline & 69 & 47.9 & 98.6 & 143.8 & 28.5 & 16.9 \\
\hline \multirow{4}{*}{ PLA/URH 70/30 } & - & 58.1 & 125.1 & 149.4 & 11.7 & 6.1 \\
\hline & 23 & 58.4 & 126.3 & 150.7 & 8.9 & 4.6 \\
\hline & 51 & 48.8 & 101.4 & 146.4 & 27.8 & 14.4 \\
\hline & 69 & 47.6 & 98.7 & 143.1 & 28.4 & 14.7 \\
\hline \multirow{4}{*}{ PLA/URH $60 / 40$} & - & 58.4 & 124.1 & 149.4 & 9.0 & 4.0 \\
\hline & 23 & 58.5 & 126.9 & 150.7 & 7.0 & 3.1 \\
\hline & 51 & 51.7 & 105.3 & 149.5 & 19.6 & 8.7 \\
\hline & 69 & 48.3 & 98.9 & 143.4 & 22.1 & 9.8 \\
\hline
\end{tabular}

${ }^{*}$ Two fusion peaks observed in PLA and PLA/RH composites immersed at 51 and $69^{\circ} \mathrm{C}$

absorption at $51{ }^{\circ} \mathrm{C}$. However, this may be subjected to further scrutiny. Intensities of the melting peaks also increased slightly at higher temperatures. However, two melting peaks were observed in the products that had been hydrolyzed in water at 51 and $69^{\circ} \mathrm{C}$. Neither of these peaks could be associated with thermal transitions of rice hulls as this biomass does not melt or crystallize and also on the fact that two peaks appeared in PLA, which did not contain rice hulls. It is therefore permissible to associate these peaks to the melting of hydrolytic degradation products of PLA since they were only visible in the products that had been subjected to hydrolysis at higher temperatures.

The summary of DSC results presented in Table 2 show very small increase in the glass transition temperature $\left(T_{\mathrm{g}}\right)$ of PLA by $0.4^{\circ} \mathrm{C}$ at the immersion temperature of $23^{\circ} \mathrm{C}$. This small increase could be associated with minor changes in the polymer that might have influenced a slight increase of its high molecular weight fractions. It is shown further that $T_{\mathrm{g}}$, the crystallization temperatures $\left(T_{\mathrm{c}}\right)$ and melting temperatures $\left(T_{\mathrm{m}}\right)$ also decreased probably due to hydrolysis of the polymer at higher water temperatures. Kale et al. [16] applied Fox-Flory equation to demonstrate the reduction of the $T_{\mathrm{g}}$ with the decrease of the number average molecular weight $\left(\bar{M}_{\mathrm{n}}\right)$ of commercial PLA products during degradation in a compost. Based on this relation, which has also been applied a couple of years earlier [22], we can associate the decrease of the $T_{\mathrm{g}}$ of PLA with the reduction of its molecular weight due to hydrolysis. Perhaps there was a molecular weight degradation during water absorption that would be associated with the cleavage of the chain at $-\mathrm{C}-\mathrm{O}-$ ester group by water molecules due to hydrolysis. To verify whether these changes are related to the molecular weight degradation of PLA or not, a molecular weight analysis was conducted by SEC. The results are shown in the corresponding section. Nevertheless, we cannot fully associate the physical changes of PLA products that were immersed at $23^{\circ} \mathrm{C}$ with any cross-linking or recombination reactions of the polymer under water at that temperature.

Change of crystallinity $\left(\chi_{\mathrm{c}}\right)$ and fusion enthalpies $\left(\Delta H_{\mathrm{m}}\right)$ due to hydrolysis of PLA were also examined. It is shown in Table 2 that the crystallinity and enthalpies of fusion of PLA decreased slightly at $23^{\circ} \mathrm{C}$. However, it is shown further that there was a remarkable transformation of the amorphous region of PLA into crystalline phases at higher hydrolysis temperatures as shown by an increase of crystallinity. The largest transformation of the PLA to crystalline domains was achieved at $69^{\circ} \mathrm{C}$, which was accompanied with maximum reduction of the $T_{\mathrm{g}}$ and $T_{\mathrm{m}}$. Hydrolysis of the semi-crystalline PLA starts in the amorphous region transforming these domains to crystalline phases and it increases with the hydrolysis temperature [23]. The crystallinity can decrease if hydrolysis is extended in the crystalline domains once the hydrolysis of the amorphous region is over. The decrease of the $T_{\mathrm{g}}$ can be 
related to molecular weight degradation as demonstrated previously using Fox-Flory equation [16]. It can thus be suggested that the development of crystalline phases in this polymer during hydrolysis at higher temperatures was accompanied with the reduction of its molecular weight. This proposition can also be verified by studying the molecular weight degradation of this polymer.

The representative results of the influence of hydrolytic degradations on the thermal stability of PLA and its composites as determined by TGA are shown at Figure 3. It is shown that all PLA products degraded in one major stage between 220 and $389^{\circ} \mathrm{C}$. A secondary stage for the PLA/RH composites, which is shown between 370 and $530^{\circ} \mathrm{C}$, was associated with the degradation of lignin and cellulose products in rice hulls. Additionally, there are two degradation stages between 220 and $333^{\circ} \mathrm{C}$ and from 333 to $389^{\circ} \mathrm{C}$ for the PLA product that was immersed at $69^{\circ} \mathrm{C}\left(\mathrm{PLA}-100 \mathrm{WA} 69^{\circ} \mathrm{C}\right)$. These stages could be ascribed to thermal degradation of two hydrolytic degradation products of PLA with distinct thermal stabilities. Since these changes resulted from the hydrolysis of the polymer, it may be plausible to ascribe the two degradation stages to the decomposition of hydrolytic products with distinct molecular weights. By relating the decomposition temperature to the molecular weights as proposed by Kale et al. [16] using an expression similar to Fox-Flory equation, a higher molecular weight product decomposes at higher temperature and viceversa. This implies that the first decomposition stage of this product could be attributed to the degradation of low molecular weight fractions of the polymer while the second stage involved hydrolytic degradation products with slightly higher molecular weight fractions. However, the legitimacy of this

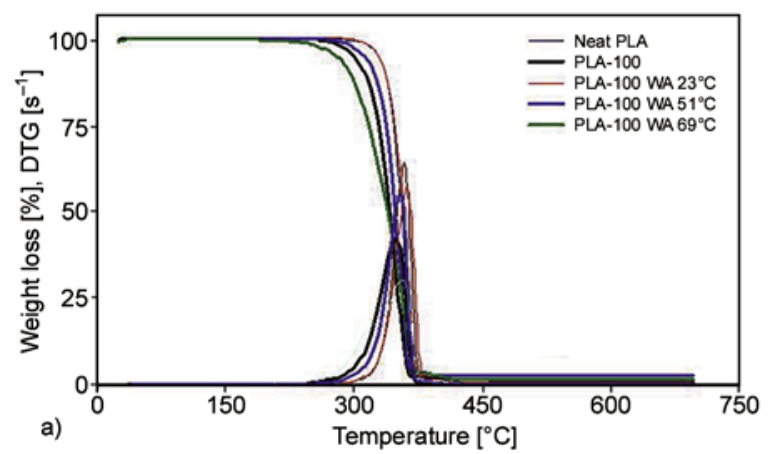

assertion relies on the agreement with the molecular weight degradations results. It can also be shown further that peaks of maximum degradation zones for PLA and the composites that were immersed at $23^{\circ} \mathrm{C}$ generally occurred at higher temperatures. The high thermal stability of PLA was probably due to an increase of higher molecular weight fractions in the polymer during hydrolysis at this temperature. These products also lost large weights in the main degradation zones compared with similar products that were immersed at higher temperatures as indicated by stronger DTG curves peaks.

The influence hydrolytic degradations on the kinetics of thermal degradation of PLA were also studied using Horowitz and Metzeger [24] model shown in Equation (4).

$\ln \frac{1-C^{1-\mathrm{n}}}{1-n}=\frac{E(\Delta T)}{R T_{\max }^{2}}$

where $C=\left(w-w_{\mathrm{f}}\right) /\left(w_{0}-w_{\mathrm{f}}\right)$ is the fraction of the sample lost, $E$ is the activation energy, $T_{\max }$ is the temperature at maximum weight loss obtained from the peaks of DTG curves, $R$ is the universal gas constant, $\Delta T=T-T_{\max }$ and $n$ is the order of reaction.

The reaction orders, $\mathrm{n}$, estimated from $C_{\max }=$ $n^{1 /(1-n)}$ were found to range from 0.6 to $\sim 1.0$. The kinetics of thermal degradation of PLA was approximated using the first order reaction of this model. The left term of Equation (4) was reduced to $\ln [\ln \alpha]$ and $E$ was obtained from the slope of the linear relation $\ln \left[\ln \left(w_{0}-w_{\mathrm{f}}\right) /\left(w-w_{\mathrm{f}}\right)\right]$ versus $\Delta T$. The results shown in Table 3 suggest that the thermal stability of PLA was slightly reduced due to processing. After hydrolysis of PLA in water at higher temperatures, the activation energy of thermal degradation generally decreased except at the immersion temperature of $23^{\circ} \mathrm{C}$, where it slightly increased. In

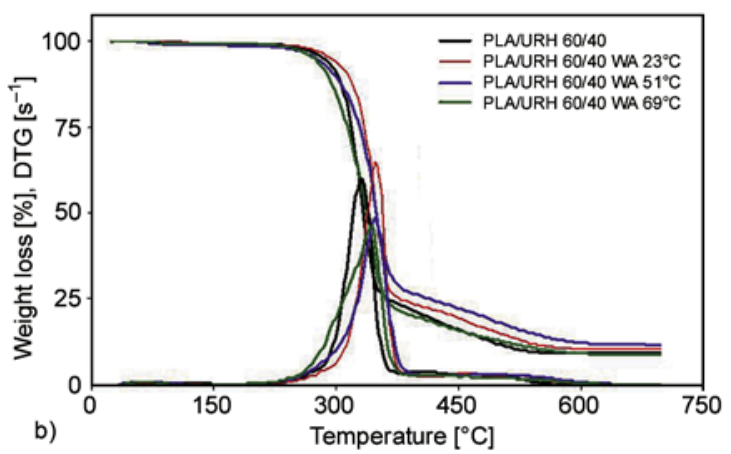

Figure 3. Thermograms of (a) PLA and (b) PLA/URH 60/40 composites products before and after water absorption at different temperatures 
Table 3. Kinetic parameters of thermal and hydrolytic degradation of PLA and its rice hulls composites

\begin{tabular}{|c|c|c|c|c|}
\hline Product & $\begin{array}{c}\text { Decomposition step } \\
{\left[{ }^{\circ} \mathrm{C}\right]}\end{array}$ & $\begin{array}{l}\mathbf{T}_{\max } \\
{[\mathrm{K}]}\end{array}$ & $\begin{array}{c}\mathbf{E} \\
{[\mathrm{kJ} / \mathrm{mol}]}\end{array}$ & $\begin{array}{c}\text { Estimated reaction } \\
\text { order, } n\end{array}$ \\
\hline PLA-Neat & $291-375$ & 357.5 & 332.5 & 1.2 \\
\hline PLA-100 (control) & $266-371$ & 350.5 & 224.0 & 0.6 \\
\hline PLA-100WA23 ${ }^{\circ} \mathrm{C}$ & $291-375$ & 361.0 & 305.8 & 1.0 \\
\hline PLA-100WA5 $1^{\circ} \mathrm{C}$ & $266-371$ & 354.0 & 250.7 & 0.7 \\
\hline PLA- $100 \mathrm{WA} 69^{\circ} \mathrm{C}$ & $231-378$ & 357.5 & 161.6 & overall \\
\hline PLA-100WA69 ${ }^{\circ} \mathrm{C}$ & $231-336$ & 357.5 & 170.0 & 1.9 \\
\hline
\end{tabular}

conjunction with SEC results, it may be possible to explain clearly and relate the changes to the molecular weight of the polymer. However, with the fact that higher molecular weight products require more energy to decompose and vice versa, the decrease in the activation energy can be related to molecular weight degradations. Concurrently, a slight increase in the activation energy observed at $23^{\circ} \mathrm{C}$ attests the proposition of the increase of high molecular weight fractions in the polymer at this temperature.

\subsection{Infrared spectroscopy analysis}

The results of infrared spectroscopy of PLA and PLA/RH composites, which were subjected to

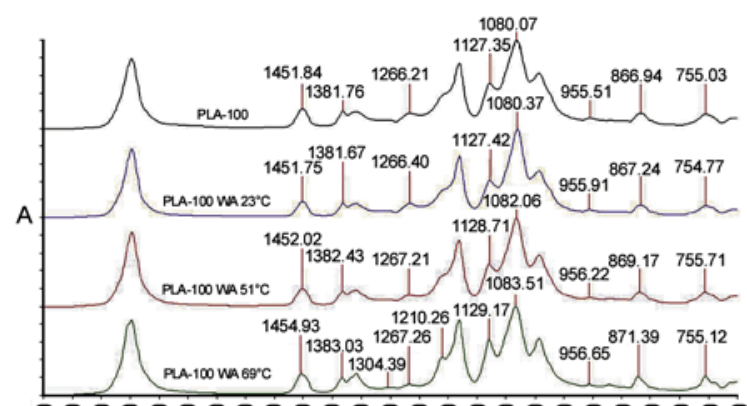

a)

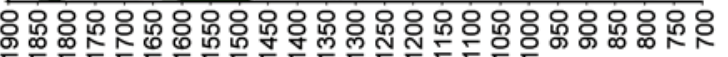

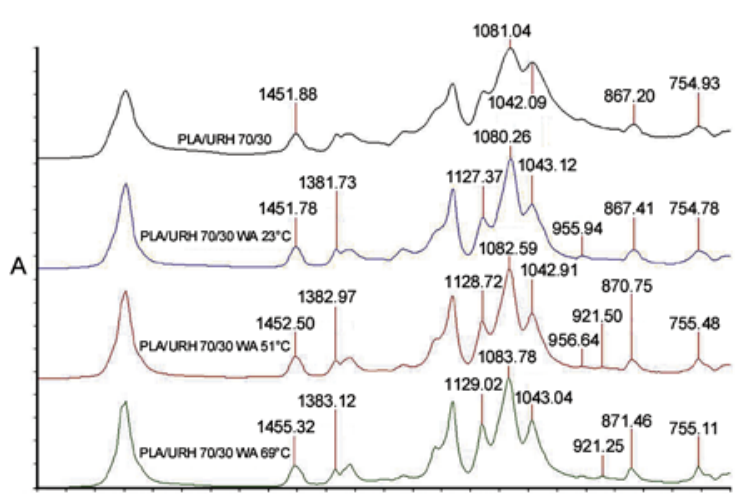

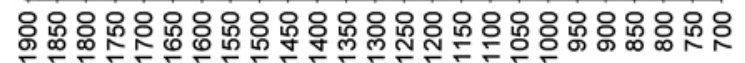

c)

Figure 4. a) Infrared spectra of PLA products due to hydrolysis at different temperatures, b) Infrared spectra of PLA/URH 80/20 composites due to hydrolysis at different temperatures, c) Infrared spectra of PLA/URH 70/30 composites due to hydrolysis at different temperatures, d) Infrared spectra of PLA/URH 60/40 composites due to hydrolysis at different temperatures 
at the $-\mathrm{C}-\mathrm{O}-$ ester bond tends to shift ester bands to lower frequencies. The results show that the carbonyl group $\mathrm{C}=\mathrm{O}$ band ascribed to ester bond did not shift. The only notable change shown on this band is a slight increase in intensity by $1.03,1.23$ and 1.14 relative to control PLA products. This change may be associated with stretching vibration that favored the hydrolysis of the polymer chains. Although a fraction of MA was used as a grafting agent between the polymer and the rice hulls, its presence could not be detected by an infrared spectroscopy in the composites between 1700 and $1600 \mathrm{~cm}^{-1}$. This could be attributed to inadequate dispersion of the little proportion of MA used in the preparation of the PLA/RH composites.

Further changes in the structure of PLA due to hydrolysis and water absorption were noted in the regions of 1451-1454 $\mathrm{cm}^{-1}, 1381-1383 \mathrm{~cm}^{-1}, 1264$ $1267 \mathrm{~cm}^{-1}, 1210 \mathrm{~cm}^{-1}, 1180-1181 \mathrm{~cm}^{-1}, 1127-$ $1129 \mathrm{~cm}^{-1}, 1080-1083 \mathrm{~cm}^{-1}, 955-956 \mathrm{~cm}^{-1}, 921 \mathrm{~cm}^{-1}$ absorptions. The $1451 \mathrm{~cm}^{-1}$ band, which is attributed to asymmetric stretching of methyl $-\mathrm{CH}_{3}$ group, shifted slightly to higher frequency by $3 \mathrm{~cm}^{-1}$ at higher hydrolysis temperatures. This is associated with changes of the hydrophobic properties of the PLA, which is conferred by the $-\mathrm{CH}_{3}$ group, during hydrolysis. The band at $1375 \mathrm{~cm}^{-1}$ assigned to symmetric deformation of methyl $-\mathrm{CH}_{3}$ group occurred at $1381 \mathrm{~cm}^{-1}$ and also shifted slightly to higher frequencies by $2 \mathrm{~cm}^{-1}$ with the increase of hydrolysis temperatures. A similar trend associated with this group can be observed at $\sim 1264 \mathrm{~cm}^{-1}$. However, their intensities decreased slightly at higher water absorption temperatures. The $1080 \mathrm{~cm}^{-1}$ ascribed to symmetric stretching of $-\mathrm{C}-\mathrm{O}-$ band of ester groups also shifted slightly to higher frequencies by 3 or $4 \mathrm{~cm}^{-1}$ due to hydrolysis at higher temperatures. This change can be attributed to strengthening of the ester bond against hydrolysis.

\subsection{Molecular weight degradation analysis}

Table 4 shows the results of molecular weights $\left(\bar{M}_{\mathrm{w}}\right.$, $\left.\bar{M}_{\mathrm{n}}\right)$ analysis of PLA that had been subjected to water absorptions at 23,51 and $69^{\circ} \mathrm{C}$. It is shown that the weight average molecular weight $\left(\overline{M_{\mathrm{w}}}\right)$ and the number average molecular weight $\left(\overline{M_{\mathrm{n}}}\right)$ of control PLA were around 153.1 and $93.9 \mathrm{kDa}$, respectively. After 30 days of water absorption at $23^{\circ} \mathrm{C}$,
Table 4. Molecular weights degradation of PLA due to water absorption at different temperatures

\begin{tabular}{|c|c|r|r|c|}
\hline Product & $\begin{array}{c}\text { Temperature } \\
{\left[{ }^{\circ} \mathbf{C}\right]}\end{array}$ & $\begin{array}{c}\overline{\mathbf{M}}_{\mathbf{w}} \\
{[\mathbf{k D a}]}\end{array}$ & $\begin{array}{c}\overline{\mathbf{M}}_{\mathbf{n}} \\
{[\mathbf{k D a}]}\end{array}$ & $\overline{\mathbf{M}}_{\mathbf{w}} / \overline{\mathbf{M}}_{\mathbf{n}}$ \\
\hline PLA-100 (control) & - & 153.13 & 93.89 & 1.631 \\
\hline PLA-100WA23 ${ }^{\circ} \mathrm{C}$ & 23 & 156.89 & 82.80 & 1.895 \\
\hline PLA-100WA51 ${ }^{\circ} \mathrm{C}$ & 51 & 42.12 & 20.38 & 2.067 \\
\hline \multirow{2}{*}{${ }^{*}$ PLA-100WA69 ${ }^{\circ} \mathrm{C}$} & 69 & 10.70 & 5.31 & 2.016 \\
\cline { 2 - 5 } & Low MW peak & 4.62 & 3.14 & 1.471 \\
\hline
\end{tabular}

${ }^{*}$ Two peaks observed

increased slightly by $3.8 \mathrm{kDa}$ while $\bar{M}_{\mathrm{w}} / \bar{M}_{\mathrm{n}}$ also increased. The increase of $\overline{M_{\mathrm{w}}} / \overline{M_{\mathrm{n}}}$ implies that the molecular weight distribution was broadened due to the increase of high molecular weight fractions. Hydrolysis and cleavage of ester bonds of PLA is said to occur randomly where longer chains of the polymer become more susceptible to cleavage than the shorter chains [16]. The reduction in $\overline{M_{\mathrm{n}}}$ observed with a subsequent increase of $\bar{M}_{\mathrm{w}}$ could be ascribed to partial cleavage of some high molecular weight chains and recombination reactions leading to addition of high molecular weight fractions in the polymer. Kale et al. [17] ascribed a similar change during their study on composting of commercial PLA products to the cross-linking or recombination reactions. However, we cannot ascertain if there was any cross-linking reaction in these products at this condition. It is shown further that as the polymer was subjected to hydrolysis at higher temperatures, both $\bar{M}_{\mathrm{w}}$ and $\overline{M_{\mathrm{n}}}$ decreased significantly. This was attributed to an increase of low molecular fragments in the polymer with subsequent broadening of molecular distributions as shown by an increase of $\overline{M_{\mathrm{w}}} / \bar{M}_{\mathrm{n}}$. This change was associated with more hydrolysis of ester bonds and more cleavage of the chains as the polymer was heated in water at higher temperatures. The cleavage was more significant at $69^{\circ} \mathrm{C}$ where the $\bar{M}_{\mathrm{w}}$ of the polymer was reduced to $10.7 \mathrm{kDa}$ in less than 9 days compared to $42.1 \mathrm{kDa}$ at $51{ }^{\circ} \mathrm{C}$ in 25 days. Despite exhibiting abnormal hardness and slight increase in the weight after redrying, the PLA that was immersed at $51^{\circ} \mathrm{C}$ only showed the reduction of molecular weights and broadening of the molecular weight distribution peak. These changes are also related to the cleavage of the molecular weight chains with subsequent increase of low molecular weight fractions in the polymer. 


\subsection{Morphological analysis}

SEM results for the morphological analysis of fracture surfaces of PLA and PLA/RH composites after water absorption at 23,51 and $69^{\circ} \mathrm{C}$ are shown in Figures 5-8. It can be shown in Figures $5 \mathrm{a}$ to $5 \mathrm{~b}$ that PLA was not substantially affected physically during water absorption at 23 and $51{ }^{\circ} \mathrm{C}$ for 30 and 25 days, respectively. However, this polymer was seriously deteriorated and shattered only in 9 days after being subjected to hydrolysis in water at $69^{\circ} \mathrm{C}$. This is explained by random shattering of the polymer matrix as shown in Figure 5c, which indicates that the polymer was fragile. It is shown further that the deterioration of the matrix in the composites was influenced by the immersion temperature as well as the contents of rice hulls. At $23^{\circ} \mathrm{C}$, the matrix did not indicate any physical deterioration as shown on the fracture surface. Fractures in these products were due to breaking of the rice hulls $(\mathrm{RH})$ and the
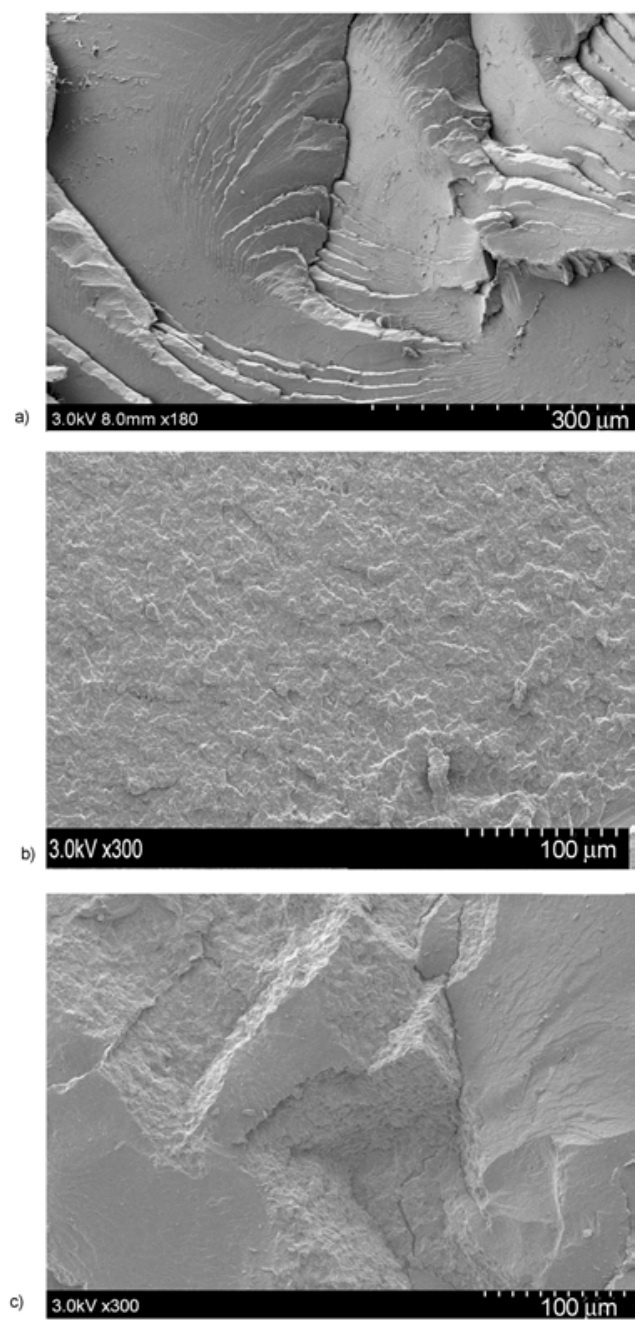

Figure 5. SEM image of the fracture surface of PLA after water absorption at (a) $23^{\circ} \mathrm{C}-30$ days, (b) $51^{\circ} \mathrm{C}$ 25 days and (c) $69^{\circ} \mathrm{C}-9$ days matrix (M) or due to partial debonding (Figures 6 to 8). However, significant development of embrittlement in the polymer matrix (M) especially at higher immersion temperatures was observed. The matrix was made fragile while most of the rice hulls $(\mathrm{RH})$ remained intact as shown in Figures $6 \mathrm{~b}$ and $6 \mathrm{c}, 7 \mathrm{~b}$ and $7 \mathrm{c}$, and $8 \mathrm{~b}$ and $8 \mathrm{c}$. Figures $9 \mathrm{a}$ and $9 \mathrm{~b}$ suggest that the rice hulls in some way enhanced the deterioration of the matrix. This is shown by the develop-

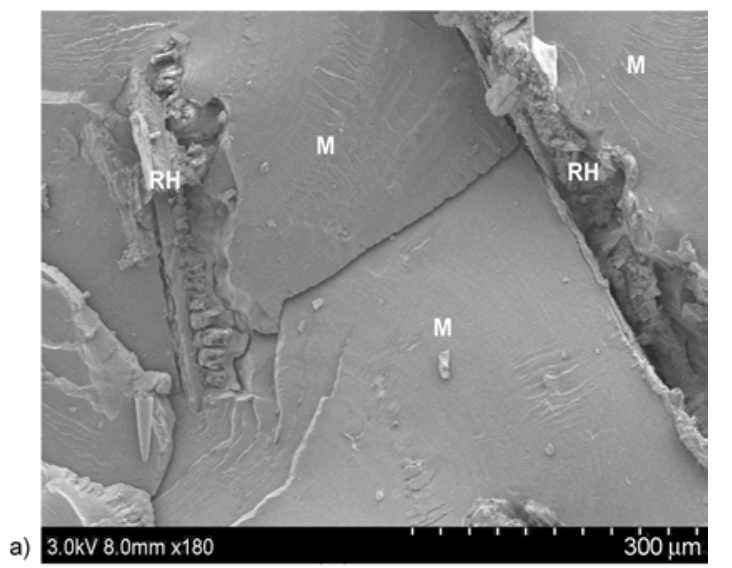

b)

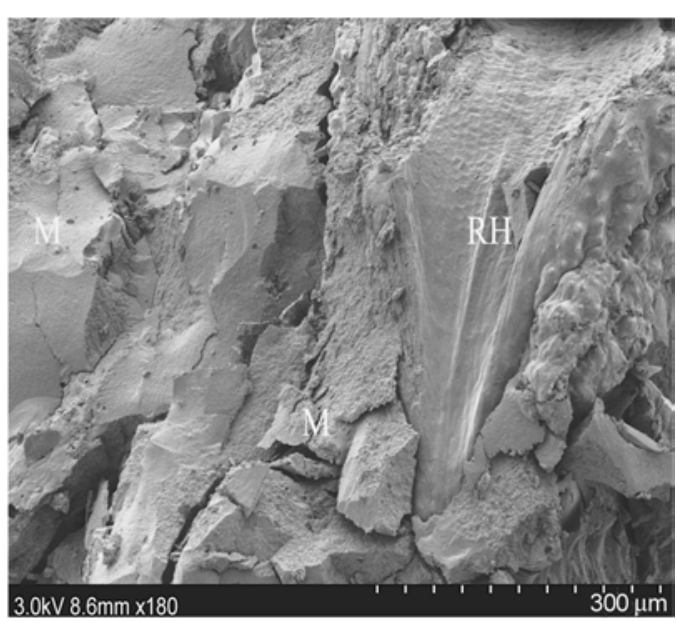

c)

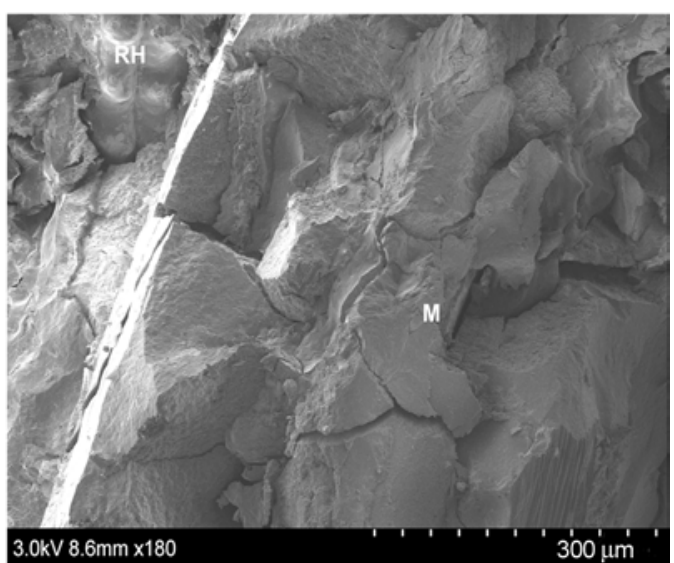

Figure 6. SEM image of the fracture surface of PLA/URH $80 / 20$ composite after water absorption at (a) $23^{\circ} \mathrm{C}-30$ days, (b) $51^{\circ} \mathrm{C}-25$ days and (c) $69^{\circ} \mathrm{C}$ 9 days 

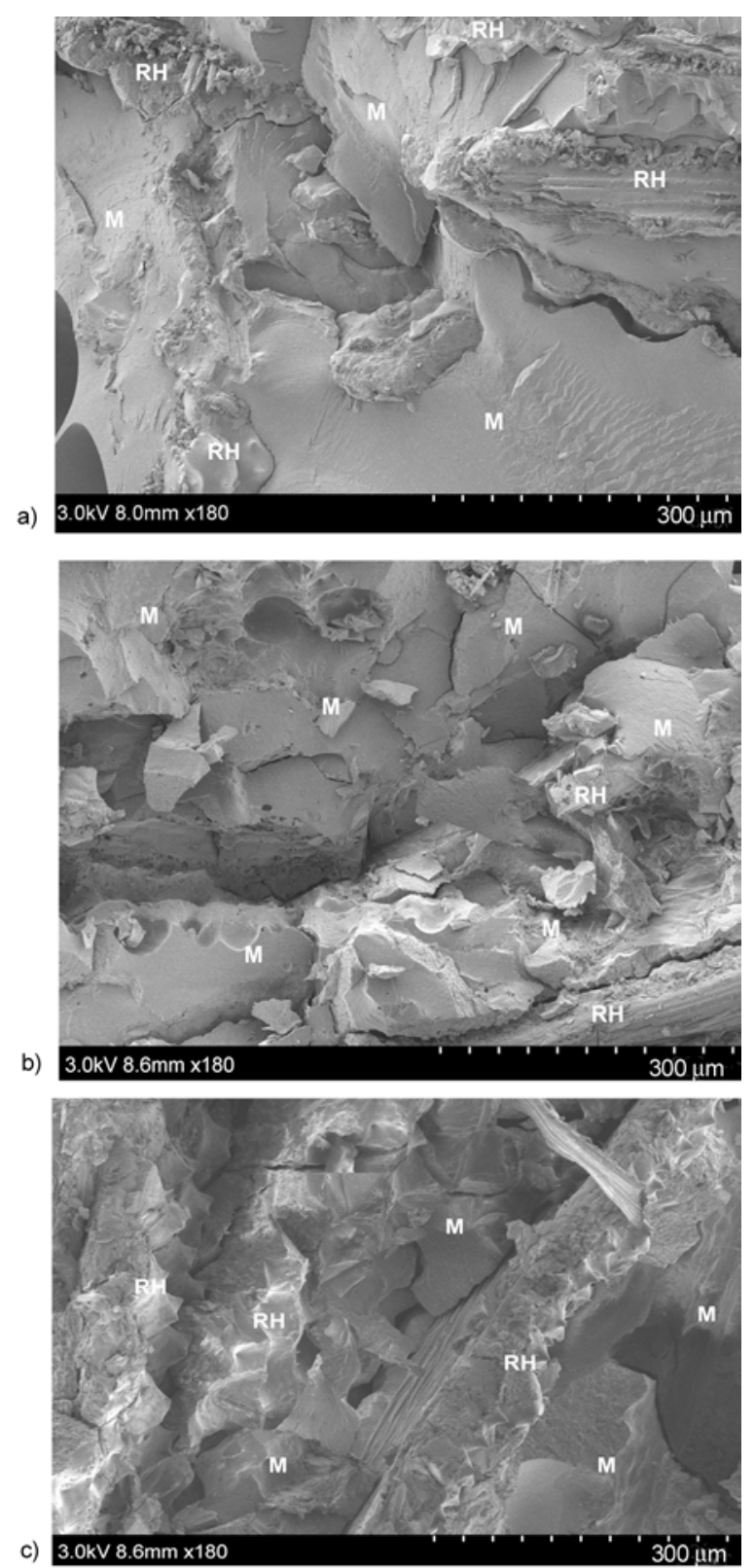

Figure 7. SEM image of the fracture surface of PLA/URH $70 / 30$ composite after water absorption at (a) $23^{\circ} \mathrm{C}-30$ days, (b) $51^{\circ} \mathrm{C}-25$ days and (c) $69^{\circ} \mathrm{C}$ 9 days

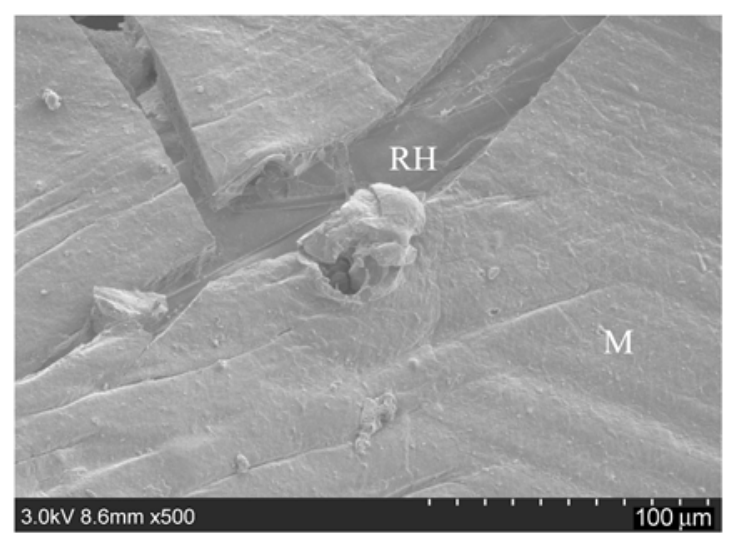

a)

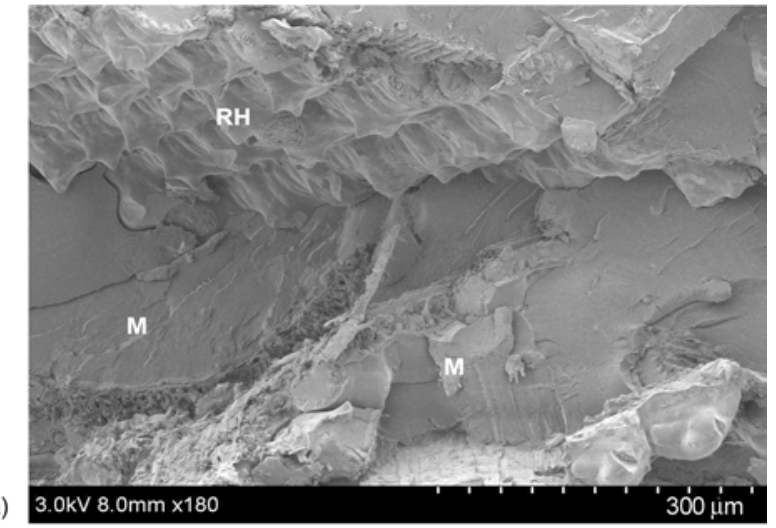

b)

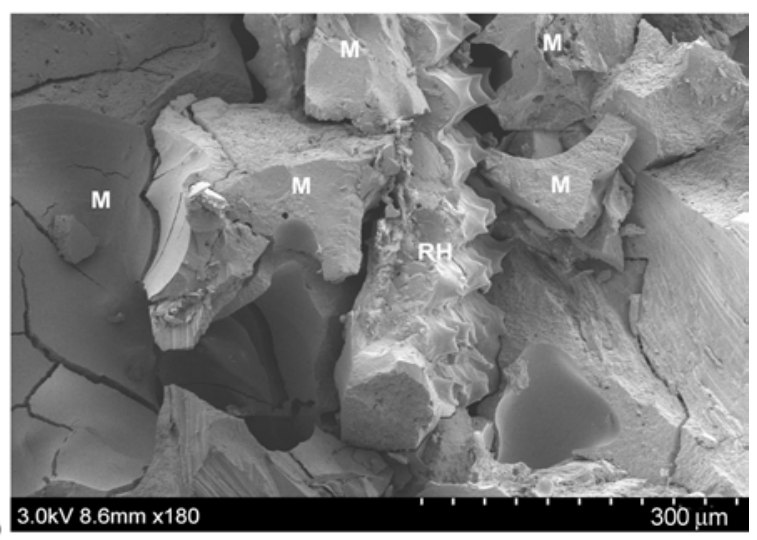

c) $\mathrm{S}-48003.0 \mathrm{kV} 1.5 \mathrm{~mm} \times 300$

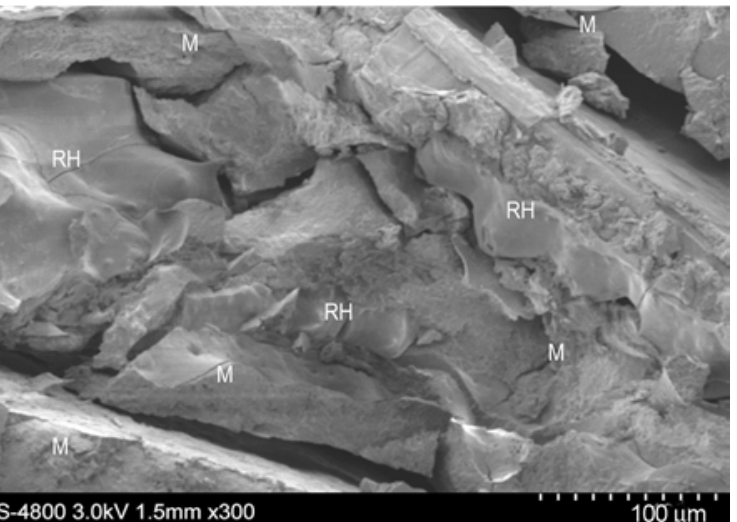

Figure 8. SEM image of the fracture surface of PLA/URH $60 / 40$ composite after water absorption at (a) $23^{\circ} \mathrm{C}-30$ days, (b) $51^{\circ} \mathrm{C}-25$ days and (c) $69^{\circ} \mathrm{C}$ 9 days

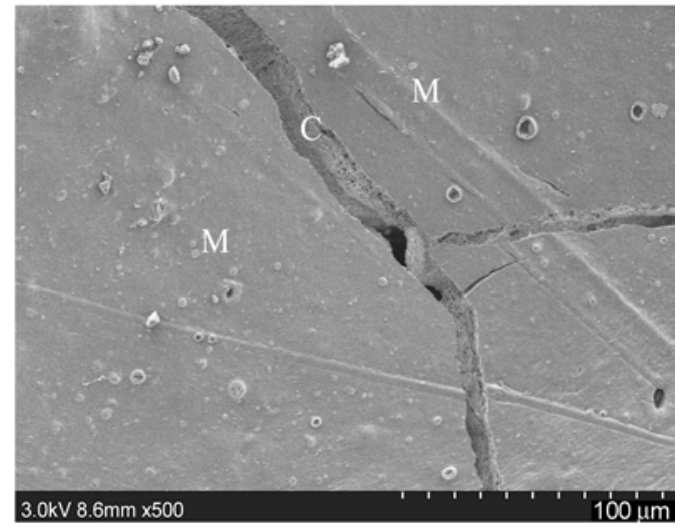

b)

Figure 9. Surface of (a) PLA/URH 60/40 and (b) PLA/URH 70/30 composites after water absorption at $51^{\circ} \mathrm{C}-25$ days 
ment of cracks (C) on the surface of the composite, which were most probably attributed to the swelling of the rice hulls $(\mathrm{RH})$ as shown in Figure 9a. It might have been the swelling of the rice hulls during water absorption that accelerated the fragmentation of the weakened matrix.

\section{Conclusions}

Degradation of PLA and PLA/RH composites due to hydrolysis in water was influenced significantly by the temperature of water. At the mesophilic temperature $\sim 23^{\circ} \mathrm{C}$, these products were fairly stable. They absorbed between 0.87 and $9.2 \%$ water in 30 days with no appreciable physical and chemical changes as revealed by SEM, infrared spectroscopy and SEC, respectively. However, close to the glass transition temperature $\left(T_{\mathrm{g}}\right)$ of PLA at $51{ }^{\circ} \mathrm{C}$, PLA started to show remarkable physical and chemical deteriorations. The rate of water diffusion and degradation in the composites increased significantly above the $T_{\mathrm{g}}\left(69^{\circ} \mathrm{C}\right)$ leading to saturation in less than 9 days. This was accompanied with the development of fragility in the material as revealed by SEM and an increase in crystallinity by $24 \%$. The $T_{\mathrm{g}}$ also reduced significantly by $13^{\circ} \mathrm{C}$ whereas the average molecular weight of the polymer decreased to $\sim 42100$ and $\sim 10700 \mathrm{Da}$ at 51 and $69^{\circ} \mathrm{C}$, respectively. These changes were associated with the hydrolytic degradation of PLA. Rice hulls in some way enhanced indirectly the disintegration of the matrix during their water absorption and swelling as was suggested by SEM. The degradation of PLA due to hydrolysis in water was also demonstrated by the reduction of the thermal stability of its products.

\section{Acknowledgements}

This publication has been produced during my scholarship period between September 2009 and August 2010 at the Royal Institute of Technology, thanks to a Swedish Institute scholarship grant. We also thank the management and staff members in the department of Fibre and Polymer Technology at the Royal Institute of Technology for supporting this study. In this category, we also wish to acknowledge the cooperation granted by members of the Sigbritt's (SK) group. We lastly express our thanks to the University of Dar es salaam for granting a study leave and supporting the first co-author.

\section{References}

[1] García M., Garmendia I., García J.: Influence of natural fiber type in eco-composites. Journal of Applied Polymer Science, 107, 2994-3004 (2008).

DOI: $10.1002 /$ app. 27519

[2] Taib R. M., Ramarad S., Mohd Ishak Z. A., Todo M.: Properties of kenaf fiber/polylactic acid biocomposites plasticized with polyethylene glycol. Polymer Composites, 31, 1213-1222 (2009).

DOI: $10.1002 /$ pc. 20908

[3] Bax B., Müssig J.: Impact and tensile properties of PLA/cordenka and PLA/flax composites. Composites Science and Technology, 68, 1601-1607 (2008). DOI: $10.1016 /$ j.compscitech.2008.01.004

[4] Hu R., Lim J-K.: Fabrication and mechanical properties of completely biodegradable hemp fiber reinforced polylactic acid composites. Journal of Composites Materials, 41, 1655-1669 (2007). DOI: $10.1177 / 0021998306069878$

[5] Lee S-H., Ohkita T., Kitagawa K.: Eco-composite from poly(lactic acid) and bamboo fiber. Holzforschung, 58, 529-536 (2004).

DOI: $10.1515 / \mathrm{HF} .2004 .080$

[6] Tokoro R., Vu D. M., Okubo K., Tanaka T., Fujii T., Fujiura T.: How to improve mechanical properties of polylactic acid with bamboo fibers. Journal of Materials Science, 43, 775-787 (2008).

DOI: $10.1007 / \mathrm{s} 10853-007-1994-\mathrm{y}$

[7] Huda M. S., Drzal L. T., Misra M., Mohanty A. K.: Wood-fiber-reinforced poly(lactic acid) composites: Evaluation of the physicomechanical and morphological properties. Journal of Applied Polymer Science, 102, 4856-4869 (2006).

DOI: $10.1002 /$ app.24829

[8] Ganster J., Fink H-P.: Novel cellulose fibre reinforced thermoplastic materials. Cellulose, 13, 271-280 (2006). DOI: $10.1007 / \mathrm{s} 10570-005-9045-9$

[9] Ahmad I., Abu Bakar D. R., Mokhilas S. N., Ram A.: Direct usage of products of poly(ethylene terephthalate) glycolysis for manufacturing of rice hull/unsaturated polyester composite. Iranian Polymer Journal, 16, 233-239 (2007).

[10] Gerardi V., Minelli F., Viggiano D.: Steam treated rice industry residues as an alternative feedstock for the wood based particleboard industry in Italy. Biomass and Bioenergy, 14, 295-299 (1998). DOI: 10.1016/S0961-9534(97)10042-3

[11] Ndazi B. S., Karlsson S., Tesha J. V., Nyahumwa C. W.: Chemical and physical modifications of rice husks for use as composite panels. Composites Part A: Applied Science and Manufacturing, 38, 925-935 (2007). DOI: $10.1016 /$ j.compositesa.2006.07.004 
[12] Rozman H. D., Musa L., Abubakar A.: Rice huskpolyester composites: The effect of chemical modification of rice husk on the mechanical and dimensional stability properties. Journal of Applied Polymer Science, 97, 1237-1247 (2005).

DOI: $10.1002 / a p p .21268$

[13] Shukla B. D., Ojha T. P., Gupta C. P.: Mechanical and physical properties of huskboards. Agricultural Mechanization in Asia, Africa and Latin America, 16, 53-60 (1985).

[14] Vroman I., Tighzert L.: Biodegradable polymers. Materials, 2, 307-344 (2009). DOI: $10.3390 / \mathrm{ma} 2020307$

[15] Kale G., Auras R., Singh S. P.: Comparison of the degradability of poly(lactide) packages in composting and ambient exposure conditions. Packaging Technology and Science, 20, 49-70 (2007).

DOI: $10.1002 /$ pts. 742

[16] Kale G., Auras R., Singh S. P.: Degradation of commercial biodegradable packages under real composting and ambient exposure conditions. Journal of Polymer and Environments, 14, 317-334 (2006).

DOI: $10.1007 / \mathrm{s} 10924-006-0015-6$

[17] Kale G., Auras R., Singh S. P., Narayan R.: Biodegradability of polylactide bottles in real and simulated composting conditions. Polymer Testing, 26, 1049 1061 (2007).

DOI: $10.1016 /$ j.polymertesting.2007.07.006
[18] Yew G. H., Mohd Yusof A. M., Mohd Ishak Z. A., Ishiaku U. S.: Water absorption and enzymatic degradation of poly(lactic acid)/rice starch composites. Polymer Degradation and Stability, 90, 488-500 (2005). DOI: 10.1016/j.polymdegradstab.2005.04.006

[19] Mitaya T., Masuko T.: Crystallization behaviour of poly(L-lactide). Polymer, 39, 5515-5521 (1998). DOI: 10.1016/S0032-3861(97)10203-8

[20] Fischer E. W., Sterzel H. J., Wegner G.: Investigation of the structure of solution grown crystals of lactide copolymers by means of chemical reactions. Colloid and Polymer Science, 251, 980-990 (1973). DOI: 10.1007/BF01498927

[21] Jang W. Y., Shin B. Y., Lee T. J., Narayan R.: Thermal properties and morphology of biodegradable PLA/ starch compatibilized blends. Journal of Industrial Engineering and Chemistry, 13, 457-464 (2007).

[22] Jamshidi K., Hyon S-H., Ikada Y.: Thermal characterization of polylactides. Polymer, 29, 2229-2234 (1988). DOI: 10.1016/0032-3861(88)90116-4

[23] Hakkarainen M., Albertsson A-C., Karlsson S.: Weight losses and molecular weight changes correlated with the evolution of hydroxyacids in simulated in vivo degradation of homo- and copolymers of PLA and PGA. Polymer Degradation and Stability, 52, 283-291 (1996).

DOI: 10.1016/0141-3910(96)00009-2

[24] Horowitz H., Metzger G.: A new analysis of thermogravimetric traces. Analytical Chemistry, 35, 14641468 (1963). 